Etiología de la sinusitis etmoidal Bacteriology of acute and chronic ethmoid sinusitis. Brook I. J. Clin Microbiol 2005; (43): 3479-80.
La sinusitis etmoidal es una infección común; sin embargo, a diferencia de la sinusitis maxilar, su microbiología y el rol de los agentes anaeróbicos estrictos no ha sido bien estudiado. Este reporte describe la experiencia del autor en el estudio de la etiología microbiana de la sinusitis etmoidal. Metodología: Se analizan 43 pacientes (26 con sinusitis aguda y 17 con sinusitis crónica) entre los años 1975 y 2000. Sólo se incluyeron aquellos pacientes con clínica de sinusitis (cefalea, fiebre, descarga nasal, etc.), signos radiológicos de sinusitis, cultivos etmoidales positivos y biopsia que demostrara inflamación de la mucosa. Se consideró sinusitis aguda o crónica si los síntomas duraban menos o más de un mes, respectivamente. El rango de edad de los pacientes estudiados fue de 6 a 67 años (promedio 47); 31 eran de sexo masculino y 11 tenían menos de 18 años. Las muestras fueron obtenidas durante la cirugía y transportadas en jeringa sellada o empleando medio de transporte para anaerobios. En cada una de ellas se realizó cultivo corriente y para anaerobios según métodos microbiológicos tradicionales. No se realizó cultivo de hongos. Además se realizó hemocultivos en 21 pacientes (14 agudos y 7 crónicos). Resultados: En sinusitis aguda se obtuvieron 47 aislados (47/26), 37 aerobios y 10 anaerobios estrictos. En 18 casos se obtuvo sólo agentes aeróbicos (69\%), 2 casos presentaron sólo anaerobios estrictos (8\%) y etiología mixta (aerobios/anaerobios) en 6 casos $(23 \%)$. Los microorganismos aeróbicos más frecuentes fueron Streptococcus pneumoniae $y$ Haemophilus influenzae. Entre los anaerobios estric- tos predominaron Peptostreptococcus sp y Propionibacterium acnes. En 8 muestras se obtuvo 9 cepas productoras de $\beta$-lactamasas (31\%). En sinusitis crónica se obtuvo 68 aislados (68/17): 27 aerobios y 41 anaerobios estrictos. En 2 casos se obtuvo sólo agentes aeróbicos $(12 \%)$, en 7 sólo anaerobios estrictos (41\%) y etiología mixta en 8 casos (47\%). Los agentes aeróbicos más frecuentes fueron bacilos gramnegativos y Staphylococcus aureus. En los anaerobios estrictos predominaron los bacilos gramnegativos (Prevotella, Porphyromonas y Bacteroides sp), Peptostreptococcus y Fusobacterium sp. En 20 muestras se obtuvo 29 cepas productoras de $\beta$-lactamasas (47\%). En 6 casos se recuperó los mismos agentes en el cultivo etmoidal y en sangre. Discusión y comentario: El estudio etiológico de las sinusitis es complejo debido a que la obtención de una muestra representativa requiere de procedimientos invasores como la punción o la cirugía, además de un transporte adecuado para recuperar anaerobios estrictos. Este estudio, metodológicamente adecuado, muestra las etiologías más frecuentes, tanto en sinusitis etmoidal aguda como crónica, destacando la presencia de S. pneumoniae y Haemophilus sp en la primera, así como el rol de bacilos gramnegativos y anaerobios estrictos en la última. Además se discuten las alternativas terapéuticas más efectivas considerando el hallazgo de un porcentaje importante de cepas productoras de $\beta$-lactamasas, que requieren una terapia con antimicrobianos efectivos contra ellas, así como antibacterianos que tengan acción contra anaerobios estrictos, especialmente en los cuadros crónicos.

Mónica Lafourcade $R$.

\section{Gatifloxacina, hiperglicemia e hipoglicemia Glucose homeostasis abnormalities associated with use of gatifloxacin Clin Infect Dis. Frothingham $R$. Clin Infect Dis 2005; 41: 1269-76.}

Las quinolonas son uno de los grupos de antimicrobianos más utilizados en el mundo. En E.U.A., el año 2004 se dispensaron 30.000 .000 de prescripciones de quinolonas en farmacias ambulatorias. En dicho país las quinolonas de mayor uso fueron ciprofloxacina, levofloxacina, gatifloxacina y moxifloxacina. Constituyen un grupo de fármacos seguros, cuyos efectos adversos (EA) más frecuentes son compromiso gastrointestinal y sobre el SNC; la descripción de EA con estas moléculas ha sido poco frecuente en los ensayos clínicos. Sin embargo, el desarrollo de quinolonas de tercera generación, activas sobre bacterias Gram positivas, particularmente Streptococcus pneumoniae, se caracterizó por la descripción de toxicidad con una serie de nuevas moléculas: temafloxacina, trovafloxacina, grepafloxacina y sparfloxacina, que motivaron el retiro de ellas del mercado farmacéutico norteamericano. Gatifloxacina fue aprobada por la FDA en diciembre de 1999; con posterioridad a su aprobación, se han publicado varios artículos sobre la asociación de gatifloxacina con EA sobre la homeostasis de la glucosa. El objetivo del trabajo fue comparar la frecuencia de EA producidas por gatifloxacina y otras quinolonas de amplio uso (ciprofloxacina, levofloxacina y moxifloxacina) en la homeostasis de la glucosa. Se revisó en forma retrospectiva, desde noviembre de 1997 a septiembre del 2003, la base de datos sobre efectos adversos de la FDA. Esta base de datos Adverse Events Reporting System recibe información espontánea de EA que surge, tanto de la industria farmacéutica como de profesionales de la salud y otros. Se eliminaron del estudio los informes de EA que fueran duplicados o que procedieran desde fuera de E.U.A. El sistema EpiInfo fue usado para el análisis estadístico. Las cuatro quinolonas estudiadas dan cuenta aproximadamente de $95 \%$ del total de quinolonas prescritas en E.U.A. Después de eliminar los reportes de EA duplicados u originados fuera de 